\title{
¿El único fundamento posible de la ética?
}

\author{
ENRIOUE ROMERALES \\ Universidad Autónoma de Madrid
}

Según muchos filósofos solamente Dios puede constituir el fundamento de la existencia de valores morales absolutos. Según un grupo más reducido, no es la naturaleza divina, ni menos su mera existencia, lo que puede fundamentar adecuadamente la moral, sino sólo su Voluntad. ¿Puede en verdad fundamentarse la moral en los mandatos divinos? $\mathrm{Y}$, caso de que pueda, ¿debe hacerlo, o existen modos alternativos y preferibles de fundamentar la moral?

Con el Eutifrón de Platón (10 a) comienza el problema de la relación entre la moral y la religion. Alli se plantea la cuestión de si lo pío es querido por los dioses porque es pio o de si es pío por ser caro a los dioses -como veremos, el 'porque' (on) empleado por Platón es crucial-. Frecuentemente se ha estimado que la segunda opción del dilema representa la postura más tarde atribuida (acaso injustamente) a Ockham: que 'querido por Dios' es precisamente el significado de "bueno' al igual que 'odiado por Dios' es el significado de 'malo'. Sin embargo, es menester observar que la posición ockhamista no es propiamente una fundamentación de la moral en la religión, sino una reducción de la moral a la re. ligión. En efecto, para que $X$ sea el fundamento de $\mathrm{Y}$ es menester que $\mathrm{X} e$ $Y$ sean distintos, sin embargo, de atenernos a la postura ockhamista, la moral y aquella parte de la religión que expresa los mandatos divinos serfan conceptualmente idénticas.

Como es conocido, Hume denuncio en su Treatise la invalidez de todos los razonamientos que partiendo de ciertos hechos trataban de extraer conclusiones acerca de lo que debe o no debe ser el caso. Tal proceder fue denominado posteriormente por Moore "falacia naturalista». Pues bien, la falacia naturalista acecha a la segunda alternativa del dilema, puesto que en realidad es de ahechos" tocantes a la voluntad divina de donde esta alternativa trata de deducir tanto nuestras obligaciones como nuestras prohibiciones morales ( $($ Dios ordena p» luego ues obligatorio $p m$ ). No obstante, el ockhamista puede convertir el argumento en válido con sólo añadir a modo de premisa el principio P: «si y sólo si Dios ordena (o prohibe) $\mathrm{p}$ es moralmente obligatorio (o incorrecto) p». Frankena $(1973,18)$ hace notar que, con todo, por ser ético dicho principio, al hacer uso de él ya no estamos basando la etica exclusivamente en la religión, de manera que para evitar la falacia naturalista las fundamentaciones teologicas de la moral se convierten en ético-teologicas.

Pero la estrategia ockhamista diseña la siguiente salida: considerar $P$ no como un principio ético, sino meramente lógico. $\mathrm{Si}$ 'obligatorio' o 'se debe' significa 'ordenado por Dios', entonces -y sin necesidad de premisas éticas adicionales- podemos deducir directamente conclusiones éticas a partir de premisas puramente teológicas. Con ello podrá a la vez reducirse completamente la ética a la religión y evitarse la falacia naturalista. Por supuesto, la 
cuestión relevante entonces es si existen razones independientes para aceptar tal principio. Ahora bien, si suponemos que $P$ es analítico, entonces la moral y la religion (o una parte de ella) son conceptualmente equivalentes o idénticas, de modo que nunca podra la una ser el fundamento de la otra. Así, decir wes el caso que $\mathrm{X}$ porque es el caso que $Y$ ” es expresar una relación de fundamentación: $\mathrm{X}$ es la causa, la razón o el fundamento de que $Y$ sea el caso. Por ejemplo, si pregunto «por qué es veloz el guepardo" no constituirá una respuesta adecuada decir "porque corre mucho", pues «ser veloz" significa "correr muchon. Si serfa adecuado responder "porque tiene un cuerpo estilizado y patas muy fuertes", "porque tiene ciertos músculos hiperdesarrollados», etc. Por la misma razon, si siguiendo a Ockham decimos que 'bueno' significa 'querido por Dios', entonces no tendra sentido decir que decir la verdad es bueno porque lo quiere Dios. La postura ockhamista, por lo tanto, no constituye propiamente una fundamentación de la moral en la religión o en Dios, sino una doctrina lingǘstico-conceptual: que el término 'bueno' (u 'obligatorio' o 'incorrecto') significa "querido por Dios' (u 'ordenado por Dios' o 'prohibido por Dios' respectivamente). Esta doctrina es manifiestamente incorrecta, al menos en su versión lingüística, pues en ninguno de los idiomas conocidos los enunciados morales significan enunciados acerca de la voluntad de Dios. Ni siquiera los creyentes usan mayoritariamente los términos morales con ese significado. No obstante, dejando de lado que en el lenguaje común 'bueno' no signifique de hecho lo que presuponen algunos ockhamistas, el asunto crucial es que de ser asi la moral desapareceria por completo (no ya simplemente que estaría fundamentada en la religión), y dado que Eutifón se planteaba cuál era el fundamento de cual, la anterior doctrina lingǘstica no puede corresponder a ninguna de las opciones contempladas por Eutifrón. Podria, sin embargo, sostenerse que es ésta una postura que supera el dilema eludiéndolo. $\mathrm{Y}$ efectivamente, asi es: si $\mathrm{X}$ e $\mathrm{Y}$ son idénticos o conceptualmente equivalentes, carece de sentido preguntar cual fundamenta a cual. Pero acabamos de ver que en realidad no existen razones para considerar a los enunciados morales conceptualmente identicos con determinados enunciados teologicos. Por ello, siguiendo a Eutifrón, nos atendremos a los intentos de fundamentar la moral en la religión sin con ello minar la especificidad de la moral.

Comenzaremos explicitando la diferencia logica entre sfundamentar la moral en la religión" y areducir la moral a la religion», Denominaré fundamentación teológica de la moral a una hipótesis que afirme que "la accion $A$ es moralmente incorrecta si y sólo sî A está prohibida por Dios». O sea, el que Dios prohíba A será condición suficiente y necesaria para que A sea moralmente incorrecto. Es patente la relación lógica de bicondicionalidad entre el aspecto teológico y el moral del anterior principio: ambos conceptos se implican mutuamente, son coextensionales. Ahora bien, que dos conceptos se impliquen mutuamente no entraña que sean conceptualmente equivalentes, sino solo logicamente equivalentes. La equivalencia entre «incorrecto» $y$ "prohibido por Dios" deberá ser meramente extensional, no intensional. Pero para una fundamentación teologica de la moral ni siquiera la equivalencia logica da razón suficientemente de la relación entre la ética y la religión, pues lo que ella afirma no es meramente que las prohibiciones divinas coinci- 
den exactamente con las acciones moralmente incorrectas (eso seria compatible con que hubiera acciones en sf mismas incorrectas y que Dios prohibiera todas y cada una), sino que la causa, razón o fundamento de la incorrección moral de una acción dada es que Dios la prohíba. $Y$ esto implica una preeminencia ontologica o axiologica de la teologra sobre la ética (Bartley, 1971, 10-11).

La razón básica para tratar de fundamentar la moral en la religión es que no parece alcanzable un acuerdo generalizado para fundamentar la moral de otro modo. La falacia naturalista amenaza todas las éticas materiales. La ética formal no parece poder rellenar de contenido prescripciones abstractas como el imperativo categorico sin generar nuevos problemas. Una conclusión muy extendida es que la moral es algo relativo, circunstancial, condicionado, etc., objeto a lo sumo de consenso, pero no de certeza. Sin embargo, quienes profesan una religión como la cristiana, la judía o la musulmana -y no sólo ellos-, están convencidos de que la moral posee un valor absoluto. Y éste, alegan, no puede ser otro que Dios como legislador universal. Una ética basada en los mandatos divinos afirmará que solamente Dios puede ser fuente de obligacion moral objetiva y absoluta.

P. Geach $(1969,124)$ afirma que la fundamentación teológica de la moral es el único modo de superar la temida falacia naturalista, de pasar del 'es' al 'debe'. Para Geach algo es moralmente incorrecto sólo si está absolutamente prohibido, y sólo Dios puede prohibir (u ordenar) de forma absoluta. Sin Dios, como decía Dostoievski, todo está permitido. Inmediatamente surge la cuestion: ¿y cuál es la razón lógica que conecta "Dios prohibe $x$ " con "no debe hacerse $x n$ ? Al no afirmarse ya que las dos expresiones sean sinónimas o conceptualmente equivalentes esta pregunta es pertinente. La respuesta de Geach es que tal pregunta es uinsensata» [unsound] $(1969,126)$. Dado que Dios es nuestro creador y juez, plantear "cpor que he de obedecerle?" es absurdo, irracional: no podemos sopesar nuestra obediencia a Dios contra el bien que ganaríamos con la desobediencia. Geach parece querer decir que desobedecer a Dios entraña nuestra perdición, y que es absurdo buscarse a propósito la perdición. Pero si, por ejemplo, Dios nos ordenara ser crueles ¿no seria ético buscarse la perdición desobedeciéndole, por más que fuera «insensatom? Parece que la razón para obedecer a Dios latente en Geach es puramente prudencial, pero un acto prudente puede ser muy poco ético. La objecion a Geach sigue siendo que hace falta una razon moral que explique por qué uno debe obedecer a Dios (y no simplemente que le conviene o que más le vale). En suma, una fundamentación teologica de la moral afirmará que el principio $P$ es necesario, pero dado que no es analítico, hay que ofrecer razones en favor de la necesidad de $P$. Ahora bien, lo crucial es si la razón que tiene Dios para ordenarnos algo es a la vez nuestra razón para obedecer, porque de serlo, su razón sera una razón moral y entonces la moral no estarfa sometida a los mandamientos divinos, sino a la inversa.

B. Brody (1974, 143), piensa que pueden esgrimirse razones no morales para obedecer a Dios, como que Él es nuestro creador. Asf, al igual que debemos seguramente obedecer a nuestros padres, tanto más a Dios que es nuestro creador y señor. Sin embargo, cabe replicar que, de igual modo que la obediencia a nuestros padres no puede ser incondicional e irrestricta, probablemente tampoco la obediencia a Dios 
habria de serlo. Pero, sobre todo, que el deber obediencia a nuestros padres se basa en ciertas razones (ellos nos cuidaron, saben mejor lo que nos conviene, etc.) distintas del hecho de que sear nuestros progenitores, y que el deber de obedecer a Dios se deberá a razones similares ( ser, nos ama, sabe mejor lo que nos conviene). Como muestra Swinburne (1989, 127) aunque haya propiedades no morales que hagan que Dios deba ser obedecido, ello ha de deberse a alguna razón moral: "Cualquier deber de obedecer a Dios debe surgir de ciertas propiedades que 1 ll posea - p. e. ser nuestro creador-. Y el por qué estas propiedades dan lugar a una obtigación scrá la causa de algún principio general, por ejemplo, que uno debe mostrar gratitud a sus benefactores". $Y$ añade: "Nuestra asunción teologica sólo puede refinar y profundizar nuestras concepciones acerca de lo que es obligatorio y lo que es bueno, no puede conducir a su total sustitucion".

Desgraciadamente, la fundamentación teológica de la moral resulta insostenible por lo que ella implica: a) que determinadas acciones que consideramos moralmente incorrectas, como el asesinato, el genocidio o la violación, se convertirian en correctas, e incluso en obligatorias, si Dios las ordenara. $Y$ b) que Dios mismo no puede considerarse moralmente bueno. Dado que no hay más bien moral que obedecer o agradar a Dios, Dios mismo ha de estar más alla del bien y del mal. Pero lo primero es totalmente implausible, y lo segundo es incompatíble con la predicación tradicional del teísmo de que Dios es bueno (más aún, infinitamente bueno), Como ha señalado Chandler $(1985,231)$ la raiz de ambas objeciones es que los mandatos divinos, al dimanar de su sola Voluntad, son enteramente arbitrarios. Pero, si
Dios es bueno ordene lo que ordene y haga lo que haga, por el simple hecho de ser Dios, los conceptos morales de bueno y malo se desintegran, y se reemplazan por otros conceptos con un significado puramente teologico, pero amoral -como ocurria con la versión lingüistica de la teoria-.

Para evitar los problemas que plantea una estricta fundamentación teologica de la moral se han propuesto últimamente dos versiones debilitadas de ella. Según la primera, debida a R.M. Adams, los mandatos divinos son condición necesaria, pero no suficiente, de la moral. Lo verdaderamente característico de una teoría etica basada en los mandamientos divinos, según Adams, es que sin Dios no haya moral, que Dios es condición necesaria de la moral. Entonces $P$ se convierte en $P^{\prime}$ : «Solo si Dios ordena (o prohibe) p es obligatorio (o incorrecto) p». Para que algo sea moralmente obligatorio hace falta que sea ordenado por Dios y que esté de acuerdo con un patrón de conducta agapeístico $(1973,100)$. De modo que, si bien para que algo sea moralmente incorrecto ha de haber sido prohibido por Dios, el que Dios así lo disponga no es por st solo causa de que eso sea incorrecto. Esto significa que, por un lado, frente a la fundamentación teológica estricta, para una fundamentación teológica restringida de la moral algo no es obligatorio simplemente porque Dios lo ordene (ni bueno porque lo desee, ni malo porque lo prohiba), que no hay mundos posibles en los que al ordenar Dios odiar o mentir eso es bueno. Pero, por otro lado, frente a Geach, que Dios si puede logicamente (aunque no moralmente) ordenar por ejemplo practicar la crueldad por sí misma. ¿Qué pasaría en un caso as? Naturalmente, toda fundamentación teologica de la moral -restringida o no- habrá de afirmar que 
siempre es etico obedecer a Dios, pues la corrección moral consiste en eso. Pues bien, Adams afirma que en el caso de que Dios ordenara por ejemplo acciones crueles por mor de sí mismas, la moral quedaría cancelada, bloqueada. Si el creyente tuviera en un momento dado un conflicto de esa naturaleza, no podría optar racionalmente entre obedecer a Dios y seguir sus intuiciones morales agapersticas. Dado que la moral surge en la congruencia entre mandatos divinos y determinadas disposiciones morales de la razón, si ambas se contradicen la moral queda en un impasse. En tal caso, tanto obeceder a Dios como desobedecerle sería lícito $(1973,102)$ (ésta parece haber sido asimismo la postura de Ockham en cuanto al valor moral -al carácter virtuoso- de las acciones, si bien en tal caso obedecer a Dios sería la acción meritoria por lo que respecta a la moral positiva).

La postura de Adams evita así ambos problemas. Por un lado, no es cierto, pace Ockham, que Dios podria haber ordenado absolutamente cualquier cosa y que entonces eso sería bueno o incluso obligatorio (lo cual es antiintuitivo). Porque si ordenara algo contrario a los principios del amor se violaría uno de los requisitos de la moralidad. Por otro lado, los mandamientos divinos ya no son puramente arbitrarios, sino que tienen su fundamento en el carácter amoroso de la divinidad. Fundamento que constituye una razón para obedecer a Dios mejor que la simple razón de que sea nuestro creador o nuestro Señor. Es el amor divino lo que hace que Dios nos mande amar y nos prohiba odiar. $Y$ con ello, si bien Dios no es bueno en el sentido estrictamente moral, sí lo es en un sentido axiologico.

En su primera version (1973), Adams expone su teoría como un análisis del lenguaje moral típico de los cristianos y ofrece varias razones. Por ejemplo, que en el discurso ético cristiano las expresiones 'incorrecto' y 'contrario a los mandamientos divinos' suscitan las mismas actitudes emocionales y volitivas de rechazo, intención de evitarlo o sentimiento de culpabilidad por haberlo hecho. Que en el contexto ético cristiano hacer algo incorrecto posee siempre el componente religioso de pecado. $\mathrm{O}$ que un modo alternativo de tratar de averiguar si algo es incorrecto es tratar de averiguar si es contrario a la voluntad de Dios. Naturalmente, para el defensor de una fundamentación teologica restringida 'incorrecto' y 'prohibido por los mandamientos divi' nos' no pueden tener ni exactamente el mismo significado ni el mismo alcance en todos los mundos posibles, y asimismo podra haber cosas valiosas independientemente de los mandatos divinos (aunque no independientemente de la voluntad divina, pues entonces estaríamos ya ante una autonomía de la moral respecto de Dios): aquellas que, aun no habiendo sido ordenadas por Dios, sean queridas por $\mathbf{E} \mathrm{l} y$, en consecuencia, buenas (actos supererogatorios). Así, seguramente no es $\mathrm{mi}$ obligación moral marcharme a Bosnia a tratar de impedir la limpieza étnica, dado que Dios no me lo ha ordenado. Pero ello no implica que hacerlo sea moralmente indiferente: es supererogatoriamente bueno. El plantear la fundamentación teologica restringida de la moral en términos de significados hace a la teorla vulnerable a muchas de las objeciones a la version ockhamista. Hay otra dificultad, señalada por el propio Adams (1973, 116): si 'bueno' significa cosas distintas para los creyentes y los no creyentes, ¿cómo puede haber acuerdos morales entre ellos, o siquiera discusion moral? Pero en su "Divine Command Mataethics 
Modified Again* $(1979,139)$ Adams ha rectificado, y ahora presenta su teoria como una descripción, en términos de mandatos divinos, de las propiedades objetivas de la moral que todos comparten, y no en términos del significado del ídiolecto particular de los creyentes. Hay aqui otra importante reformulación: ahora el carácter amoroso de la divinidad se incluye dentro del principio $P$, con lo que tenemos $P ":$ «si y sólo si un Dios amoroso ordena (o prohibe) $\mathrm{p}$ es moralmente obligatorio (o incorrecto) p". Con ello tenemos nuevamente un bicondicional (como en la fundamentación teologica no restringida), pero en el que se incluye un rasgo divino distinto de su mera voluntad (a diferencia de las fundamentaciones teológicas estándar, que basan la moral únicamente en la voluntad divina). Adams recalca que $p^{\prime \prime}$ es metafísicamente necesario, pero no analítico, pues no es una verdad conceptual (frente a los ockhamistas y a la primera versión del propio Adams).

Ahora bien, la objeción fundamental a la teoria de Adams es en qué sentido sigue siendo una genuina fundamentación teológica de la moral, pues lo caracterfstico de tal fundamentación es que la moral se base únicamente en la Voluntad divina: en el momento en que la moral se basa en otros hechos, la teoria empieza a perder especificidad. Sin embargo, cuando se dice que la razón para obedecer a Dios es que Él es amor, se está diciendo que la razón para obedecer sus decretos no es que sean suyos, sino que emanan del amor. Seguramente esto significa que emanan del amor tal como nosotros lo entendemos, de forma que un decreto divino contrario a nuestras intuiciones básicas acerca de una conducta agapeística (p. e. ser crueles porque si) no produciŕa obligación moral. Pero entonces Dios no es ya el patrón único y áltimo de la moral, con lo que la versión de Adams es una fundamentación teológica muy debilitada. En tal caso ¿por qué no obedecer sin más a los dictámenes de nuestra razón acerca de cuáles son los cursos de acción agapeísticos? Si una conducta es buena por ser producto del amor iqué le añade moralmente el que eso haya sido ordenado o deseado por Dios? Incluso, como ha apuntado Chandler (1985, 237), la tesis de la coextensividad entre "amoroso" y "correcto" es discutible, pues podria haber actos amorosos moralmente incorrectos. De hecho el amor puede ser egoísta, posesivo o celoso, y el único modo de convertirlo en amor divino es infiltrándole componentes morales.

Existe otra posible objeción a la teoría de Adams. De ella se deduce que si Dios no existe, nada es incorrecto. Aunque para muchos defensores de las fundamentaciones teologicas esto es una ventaja, incluso una razón para aferrarse a ellas, Adams concede que es defendible que haya propiedades y relaciones morales aun si Dios no existe. ¿Refutaría esto la teoría de Adams? Lo que haría es más bien convertir $P$ en contingentemente verdadero en vez de necesario. Este es precisamente el desarrollo de P. Quinn -el autor de la otra fundamentación teológica debilitada de la moral- para quien $P$ debe reemplazarse por $P^{\prime \prime}$ : "si Dios ordena (o prohibe) $\mathrm{p}$ es moralmente obligatorio (o incorrecto) $\mathrm{p}$; ; esto es, la existencia de mandatos divinos es condición suficiente, pero no necesaria, de la moral. Quinn $(1978,9)$ comienza advirtiendo que el problema real para un partidario de la fundamentación teologica de la moral no es si obedecer o no los mandamientos divinos - sean cuales fueren - sino cómo determinar qué mandamientos poseen un genuino origen divino y cuáles no. $\mathrm{Y}$ en esa deter- 
minación las consideraciones éticas de nuestra razón deben jugar un papel fundamental. Los reparos que el partidario de una fundamentación teológica pueda poner para obedecer a un mandamiento divino se referirán solamente a la autenticidad del mandamiento. Quinn insiste en que, por lo que se refiere al mundo real, las prescripciones de la moral racional autónoma y los mandamientos divinos seguramente coinciden punto por punto. La diferencia surge con respecto a situaciones contrafácticas, con respecto a otros mundos posibles en los que Dios ordenase por ejemplo torturar. Pero si la historia de Abraham es cierta, entonces esta disparidad se ha dado incluso en el mundo real. Para salvaguardar su teoría, Quinn $(1978,15)$ advierte que, de igual modo que nuestra percepción de una orden como divina siempre es falible, también son falibles nuestras intuiciones morales, de forma que en la tesitura de Abraham no está nada claro, pese a Kant, cuál de las dos alternativas es más razonable.

Pues bien, según Quinn el único requisito para que una fundamentación teologica de la moral sea tal es que el que algo sea ordenado por Dios sea una condición lógicamente suficiente para que sea requerido. Esta versión de la teoría - llamémosla fundamentación teológica condicional- es indemne a un argumento de peso que afecta tanto a las fundamentaciones teologicas simpliciter como a la de Adams: a) supongamos que el que $p$ sea ordenado por Dios no es la única razón de que sea obligatorio $p, b$ ) entonces tiene que haber alguna otra razón distinta del que Dios mande $p$ para que $p$ sea obligatorio, c) pero esa razón seguiría siendo valida incluso si Dios no hubiera mandado $p, d$ ) luego es posible que $p$ sea obligatorio sin que sea ordenado por Dios, e) por tanto, no es necesario para que una cosa sea obligatoria que sea ordenada por Dios. Desde luego, para que este argumento - sin duda válido- sea efectivo es menester demostrar la verdad de la primera premisa. Sin embargo, dicha premisa es bastante plausible. Pues bien, mientras que las anteriores fundamentaciones de la moral son vulnerables a este argumento, la teoria de Quinn no, pues admite que algo puede ser moralmente obligatorio (o incorrecto) aunque Dios no lo ordene (o prohiba): la existencia de mandatos divinos es condición suficiente, pero no necesaria de la moral.

La teoría de Quinn tiene frente a las versiones anteriores la ventaja señalada. Pero llegados a este punto cabe preguntarse seriamente: si es compatible con la moral secular, ¿que necesidad tenemos de ella? ¿Qué viene a añadir? Además, averiguar cuáles son los mandatos divinos genuinos puede ser mucho más dificil que averiguar los dictámenes morales de la razón. En todo caso, parece que la fundamentación condicional podrá ser una opción complementaria para el creyente, pero el no creyente puede pasarse perfectamente sin ella. Sigue, empero, vigente una objeción que hace que tal teoría sea, en mi opinión, poco atractiva incluso para el creyente, pues ella implica que si Dios ordena la crueldad por st misma, eso es obligatorio, y esto (que lograba evitarlo la teorla de Adams) es antiintuitivo. La única respuesta que ofrece Quinn $(1978,109)$ es que, con respecto al mundo real, las consecuencias de su teoría y de la moral autónoma pueden ser idénticas, y que si en otro mundo posible Dios ordena ser crueles tal vez eso sea allí bueno porque nuestras intuiciones morales pueden fallar al aplicarlas a mundos posibles muy diferentes. Ahora bien, por diferente que sea un mundo posible, ha de ser lo suficientemente 
parecido al nuestro para que tenga sentido la aplicación de nuestros términos morales como 'bueno', 'malo', 'incorrecto', 'obligatorio', etc. Naturalmente, si en un mundo posible las leyes de su física, su biologfa y su psicologia hicieran que fuera posible ser torturado sin sufrir el menor daño físico o sufrimiento psicológico (el ejemplo es de Quinn), en dicho mundo posible, Dios podría permitir torturar por diversion y eso no sería incorrecto (o incluso ordenarlo, con lo que serfa obligatorio), sólo que en ese mundo 'torturar' significaria algo enteramente diferente de lo que es torturar en nuestro mundo (dicho de otro modo, en ese mundo serfa metafísicamente imposible torturar). Yo al menos no puedo concebir un mundo posible en el que torturar siga siendo torturar $\mathrm{y}$, sin embargo, «torturar niños inocentes por diversión" sea bueno.

En suma, lo que se gana por un lado con la fundamentación teológica condicional se pierde por otro. La teorfa sigue produciendo contraejemplos moralmente repugnantes, por más que quizá afecten solamente a otros mundos posibles. $Y$, además, no se ve qué necesidad hay de ella, una vez que se admite que la moral puede muy bien fundamentarse de forma independiente. Siendo así las cosas, parece no quedar otra opción que la primera alternativa del dilema del Eutifión: Dios ordena lo bueno porque es bueno. ¿No se da entonces una subordinación de Dios a la ley moral? ¿Y no implica eso una restricción de la omnipotencia y la libertad divinas? En realidad se trata sólo de falsas apariencias. Si existen principios morales necesariamente verdaderos, entonces la subordinacion de Dios a tales principios es del mismo tipo que su "subordinaciorn" a los principios lógicos. Del mismo modo que la omnipotencia divina no puede hacer que $2+2 \operatorname{sean} 5$, no puede hacer que sea moralmente mejor odiar que amar, que sea moralmente obligatorio mentir por sistema, o que sea bueno torturar niffos inocentes por diversión. Ahora bien, mientras que no hay nada que Dios pueda hacer para convertir en verdadera una contradicción, parece que sí es en principio posible que Dios ordene cosas moralmente incorrectas, por más que nunca vaya de hecho a hacerlo. Si es efectivamente posible, entonces es posible que Dios deje de ser Dios, porque la bondad infinita es un atributo lógicamente necesario de quienquiera que sea Dios, de modo que si el individuo que de hecho es Dios (digamos Yaveh) realizara una mala accion, en ese instante Yaveh ya no sería Dios (cf. Pike, 1969, 67 y ss.). Si, por el contrario, pensamos que no es posible que Yaveh se ponga en situación de cometer iniquidades dados sus demás atributos (cf. Swinburne, 1974,126 y ss.), esto es, que Dios es necesariamente bueno de Re y no sólo de Dicto, entonces es la bondad necesaria propia de la naturaleza divina lo que restringe su libertad y no nada ajeno o externo a Dios mismo, con lo que no cabe hablar de subordinacion.

En cuanto a la cuestión de cuál es el fundamento de la necesidad de los principios morales necesarios, según R. Swinburne $(1974,125)$ un enunciado como uno se debe torturar niños inocentes sólo por diversion" o como «no se debe mentir por sistema» es analítico. Nótese que los ejemplos son enunciados negativos y que hacen referencia a las razones o motivaciones (por diversión, por sistema). De ello no se sigue que, por ejemplo no sea lícito mentir en determinada ocasión (por ejemplo para ahorrar sufrimiento). En efecto, un principio positivo como "se debe decir siempre la verdad" es más discutible que los anteriores. Para evi- 
tar la paradoja de que no hay regla (moral) sin (posiblc) excepción (por ejemplo si digo «se debe respetar siernpre la vidan puede objetarse, pero $c y$ en legitima defensa?, $y$ en caso de guerra?, ¿y la pena capital?, etc), se formulan los principios en términos de hechos generalizados de carácter indubitablemente malévolo y, de paso, si es posible, se añade que no hay escondida ninguna razón noble para cometerlos. Por ejemplo, "no se debe violar", o mejor "no se debe violar a menores indefensas", o aún mejor "no se debe violar a menores indefensas por placer»; o también "no se debe cometer y propiciar el genocidion, etc. Entonces, ahora se ve por qué la restricción de la libertad divina es meramente una restricción de carácter lógico: dado que Dios es bueno por naturaleza, no ptede ordenar por ejemplo el genocidio, porque es analíticamente verdadero que el genocidio es moralmente incorrecto.

Finalmente, iquiere esto decir que para un teísta no hay ninguna diferencia ética si Dios existe o no? De ningún modo. Para el teísta es relevante éticamente y metaéticamente que Dios exista. Metaéticamente, porque si Dios existe tenemos razones adicionales para hacer aquello que de todas maneras debemos hacer. Asi, debernos abstenernos de mentir porque es moralmente incorrecto $y$ porque Dios lo ha prohibido. En segundo lugar, para el teista existen $\longrightarrow$ o puede que existan - obligaciones éticas adicionales de varios típos. 1) Las derivadas de la mera existencia de un Dios creador y benefactor, esto es, la obligación del culto divino. 2) Si el teista profesa además una fe determinada, tendrá por obligacio- nes las derivadas de los preceptos ético-religiosos específicos de su religion, como por ejemplo los sacramentos. $Y$ 3) las derivadas de mandatos divinos ocasionales particulares. Puesto que Dios tiene potestad para ordenar actos supererogatoriamente buenos, o incluso moralmente indiferentes, $y$ en tal caso eso sería nuestra obligación moral. Desde luego, la voluntad divina está constreñida sólo negativamente, esto es, Dios no debe ni puede ordenar hacer nada moralmente incorrecto, pero no tiene por que ordenar solamente lo que es nuestro deber hacer.

Aplicado esto al dilema del Eutifrón el resultado es que en algunos casos lo bueno sí es bueno porque Dios lo manda. Por ejemplo si comer cerdo es moralmente incorrecto lo es únicamente porque lo ha prohibido Dios. En este punto mi opinión si coincide con la de Quinn: tanto los mandatos divinos como la naturaleza intrínseca de las acciones son fuente de obligación moral. Pero, si per impossibile surgiera algún conflicto, Dios quedaría relegado y habrfamos de obedecer a los dictados de nuestra conciencia. En definitiva, ni la voluntad divina ni los decretos divinos que dimanen de ella pueden constituir por st mismos el fundamento de la moral, por mucho que Dios sea Omnipotente. Tal vez pueda constituir un fundamento adecuado para la moral la (bondadosa) naturaleza divina, de la cual dimanará una determinada voluntad con sus correspondientes preceptos, necesariamente en consonancia con dicha naturaleza. Pero es harto dudoso que ese sea el untico fundamento posible para la moral, por más que resultara o resulte ser de hecho el verdadero fundamento. 


\title{
REFERENCIAS
}

ADams, R.M. (1973): A Moditied Divine Command Theory of Ethical Wrongness, [en 1987, pp. 97-122].

- (1979): Divine Command Metacthics Modified Again * [en 1987, pp. 128-143].

- (1987): The Virtue of Fatith and Other Essays in Phitosophical Theology, Nueva York, Oxford, Univ, Press.

Bartlex, W.W. (1971): Religion and Morality, Londres, MacMitlan.

BroDy, B.A. (1974): «Morality and Religion Reconsidered [en Helm, 1981, pp. 141-153].

Clandler, J. (1985): aDivine Command Theories and the Appeal to Lovex, Anterican Philosophical Quarterly, 22, pp. 231-239.

Franxera, W.K. (1973): *Is Morality Logically De- pendent on Religion? [en Helm, 1981, pp. 1433].

GEACH, P. (1969); *The Moral Law and the Law of God*, en God and the Soul, Londres, Routledge \& K.P.

HeLM, P. (ed.) (1981): Divine Commands and Mo. rality, Oxford Univ. Press.

PIKE, N. (1969): *Omnipotence and God's Ability to Sin [en Helm, 1981, pp, 67-82].

QunN, F. (1978): Divine Commands and Monal Requirements, Oxford, Clarendon.

SWinburne, R. (1974): *Duty and the Will of God* [en Helm, 1981, pp. 120-134].

- (1989): Responsibility and Atonement, Oxford, Clarendon.

\section{La ética teológica en España}

\author{
MARCIANO VIDAL \\ Instituto Superior de Ciencias Morales, Madrid
}

\section{Planteamiento}

El cristianismo no es esencialmente una moral. No pertenece siquiera al tipo de religiones que, como el budismo, funcionan a modo de esabidurías morales». El cristianismo es fundamentalmente un ámbito de sentido trascendente ( $\mathrm{fe}$ ) y de celebracion religiosa (simbólica sacramental).

Sin embargo, al cristianismo le corresponde como un elemento imprescindible el realizar una praxis histórica en coherencia con la fe y con la celebración cultural. De otro modo sería una realidad «alienada" y ealienante». En definición certera, el teólogo J.M. ${ }^{\text {a }}$ González Ruiz plasmó el sentido práxico de la fe en el título de uno de los libros que adespertaron del sueño dogmáticon a muchos católicos españoles en los años sesenta y setenta: "creer es comprometersen.'

Si la fe y la celebración religiosa exigen el compromiso transformativo intramundano, la moral vivida del cristianismo no es otra cosa que la mediación práxica de esa fe y de esa celebración. A lo largo de la historia los cristianos han realizado de diversos modos ese empeño moral, que ha transformado sus propias vidas $y$ ha transformado el mundo sobre el que ejercían influjo. Por otra parte, han existido y existen variantes del cristianismo, como el catolicismo, el luteranismo, el calvinismo, el anglicanismo, la ortodoxia. Cada una de ellas tiene su peculiaridad a la hora de interpretar y de vivir la dimensión moral de la fe. ${ }^{2}$

Se puede afirmar que el catolicismo, al que me refiero directamente en es- 